\title{
Mechanical Behaviour of Inconel 718 Thin-Walled Laser Welded Components for Aircraft Engines
}

\author{
Enrico Lertora, Chiara Mandolfino, and Carla Gambaro \\ Department of Mechanical Engineering, Polytechnic School of Genoa, Via all'Opera Pia 15, 16145 Genoa, Italy \\ Correspondence should be addressed to Enrico Lertora; e.lertora@unige.it
}

Received 29 May 2014; Accepted 25 November 2014; Published 31 December 2014

Academic Editor: Hong Nie

Copyright ( 2014 Enrico Lertora et al. This is an open access article distributed under the Creative Commons Attribution License, which permits unrestricted use, distribution, and reproduction in any medium, provided the original work is properly cited.

\begin{abstract}
Nickel alloys are very important in many aerospace applications, especially to manufacture gas turbines and aero engine components, where high strength and temperature resistance are necessary. These kinds of alloys have to be welded with high energy density processes, in order to preserve their high mechanical properties. In this work, $\mathrm{CO}_{2}$ laser overlap joints between Inconel 718 sheets of limited thickness in the absence of postweld heat treatment were made. The main application of this kind of joint is the manufacturing of a helicopter engine component. In particular the aim was to obtain a specific cross section geometry, necessary to overcome the mechanical stresses found in these working conditions without failure. Static and dynamic tests were performed to assess the welds and the parent material fatigue life behaviour. Furthermore, the life trend was identified. This research pointed out that a full joint shape control is possible by choosing proper welding parameters and that the laser beam process allows the maintenance of high tensile strength and ductility of Inconel 718 but caused many liquation microcracks in the heat affected zone (HAZ). In spite of these microcracks, the fatigue behaviour of the overlap welds complies with the technical specifications required by the application.
\end{abstract}

\section{Introduction}

Nickel alloys are generally used in highly aggressive environments, where qualities such as good strength and high temperature resistance become really important.

These kinds of alloys were developed in the early to midtwentieth century, when the need to increase the efficiency of gas turbines, employed for civil and military applications, induced researchers to find new highly resistant alloys, which could offer higher strength levels, even in corrosive and hightemperature environments.

One of the most important materials employed for this kind of application is Inconel 718, a Ni-Cr-Fe based alloy characterized by excellent corrosion resistance combined with outstanding tensile, fatigue, and creep properties.

Unlike other complex Ni alloys, this material shows better welding characteristics, offering a higher resistance to postweld cracking $[1,2]$.

$\mathrm{CO}_{2}$ laser beam welding (LBW) is one of the most widely used welding processes for Inconel 718.
The high density of energy allows the material to be melted rapidly: this results in narrow deep welds, high welding rates, and low heat input that minimize distortions and extension of the HAZ.

This welding process gives the possibility of realizing small thickness welds with a full joint shape control, even on different materials, and it can be easily included in a completely automated production system.

Thanks to its characteristics, LBW is witnessing wide development in many industrial sectors, in particular in the automotive [3, 4], aerospace [5], power-plant, and military ones, where it is mandatory to make really complex welds with high quality and production standards.

Some research work has focused on the implementation of $\mathrm{Ni}$ alloy laser welded joints, which mainly concern butt joints. The first scientific works carried out using the laser as a means to join the parts are those made by Gobbi et al. [6] and Cantello et al. [7] who compared the Nd-YAG and $\mathrm{CO}_{2}$ laser techniques for the realization of high thickness Inconel 718 butt joints. During these research projects careful analysis 


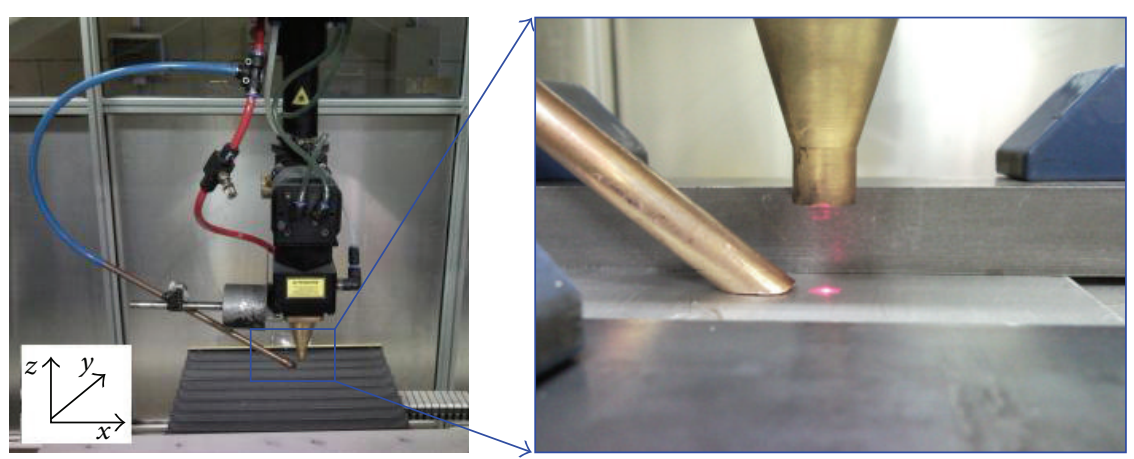

FIgURE 1: $\mathrm{CO}_{2}$ ELEN-RTM machine and a detail of the shielding gas system.

of pre- and postwelding heat treatments was carried out to eliminate the metallurgical problems related to the formation of microcracks.

Ram et al. [8] analyzed the microstructure and mechanical properties of $2 \mathrm{~mm}$ thick Inconel 718 butt joints, welded using Nd-YAG pulsed laser, focusing on different post weld heat treatment.

Hong et al. [9] carried out a study of mechanical characteristics with tensile and fatigue tests conducted on $5 \mathrm{~mm}$ thick Inconel 718 butt joints. The joints were welded with different couples of power and welding speed and different postweld heat treatments, noting a considerable increase of the mechanical resistance of the joints treated after welding. The development of new Ni superalloys led Vishwakarma et al. [10] to study the heat treatment necessary for the elimination of metallurgical defects that develop during welding. These alloys were welded with the electron beam concentrated energy technique.

Several studies have been made concerning nickel and its weldability with concentrated energy. However, besides this great diffusion, information about the effect of the laser welding process on the fatigue properties of a high performance alloy, such as Inconel 718, is still difficult to find in the literature.

In the study above, an example of small thickness Inconel 718 LBW overlap joint, used for the manufacturing of an important helicopter engine component, is reported. This joint must be characterized by a specific cross section geometry, necessary to overcome the mechanical stresses found in these working conditions without failure.

The limited thickness of the pieces to be joined does not allow postwelding heat treatments without altering the geometry of the piece; the strong distortions of the plates might seriously compromise the use of the component. In fact the heat treatment normally adopted provides solubilisation or aging at temperatures around $1000^{\circ} \mathrm{C}$. In the literature there are no studies that take into account limited material thickness to be welded. Moreover, all studies concern only butt joints. Squillace et al. [11] studying the laser weldability of $1.6 \mathrm{~mm}$ plates Ti-6Al-4V alloys give an important contribution to understanding the parameters in order to obtain the correct macrogeometry of the joint.

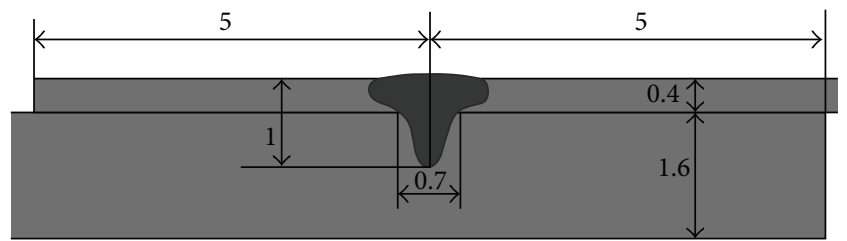

FIgURE 2: Weld cross section geometrical features.

The study of fatigue behaviour is still incomplete for butt joints and totally absent on Ni alloy lap joints. The innovation of this work lies mainly in the study of the fatigue behaviour of overlap laser joints between limited thickness Inconel 718 sheets in the absence of postweld heat treatment. Furthermore, the fatigue strength was also evaluated on the base material in order to be able to perform a comparison.

\section{Materials and Methods}

The material used in this study is Inconel 718, an age-hardenable alloy characterized by a complex chemical composition, shown in Table 1 [12].

Its high mechanical properties, guaranteed both at high and at low temperatures, are linked to the excess of $\mathrm{Nb}$ dissolved in the matrix, which results in the precipitation of the meta-stable body-centred tetragonal phase $\gamma^{\mathrm{II}}$ and of the stable orthorhombic phase $\mathrm{Ni}_{3} \mathrm{Nb}$ ( $\delta$ phase), following heat treatment [13].

In this study, as-rolled Inconel 718 sheets were lap-joined by a $\mathrm{CO}_{2}$ laser welding process. Two different thicknesses of $0.4 \mathrm{~mm}$ and $1.6 \mathrm{~mm}$ were employed realizing dissimilar joints. Each plate was $300 \mathrm{~mm}$ in length and $210 \mathrm{~mm}$ in width.

The plates were welded using a $6 \mathrm{~kW}$ maximum power $\mathrm{CO}_{2}$ ELEN-RTM machine, equipped with a nozzle delivering continuous argon shielding gas flow directly on the weld (Figure 1). Helium was used as plasma suppression gas.

A first work section was performed to create defect free welds, characterized by specific geometric parameters, required for the above mentioned industrial application. In particular, it was necessary to reach a weld width of $0.7-0.8 \mathrm{~mm}$ at the interface between the sheets and a weld penetration of 1.0-1.2 $\mathrm{mm}$ (Figure 2). 
TABLE 1: Inconel 718 chemical composition [\%] [12].

\begin{tabular}{|c|c|c|c|c|c|c|c|c|c|c|c|c|}
\hline $\mathrm{Ni}$ & $\mathrm{Cr}$ & Co & Mo & $\mathrm{Nb}$ & $\mathrm{Ti}$ & $\mathrm{Al}$ & $\mathrm{C}$ & $\mathrm{Mn}$ & $\mathrm{Si}$ & $\mathrm{B}$ & Other & $\mathrm{Fe}$ \\
\hline $50.0 \div 55.0$ & $17.0 \div 21.0$ & 1.0 & $2.8 \div 3.3$ & $4.75 \div 5.5$ & $0.65 \div 1.15$ & $0.20 \div 0.80$ & 0.08 & 0.35 & 0.35 & 0.006 & $0.3 \mathrm{Cu}$ & Bal. \\
\hline
\end{tabular}

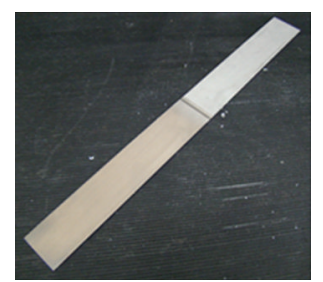

(a)

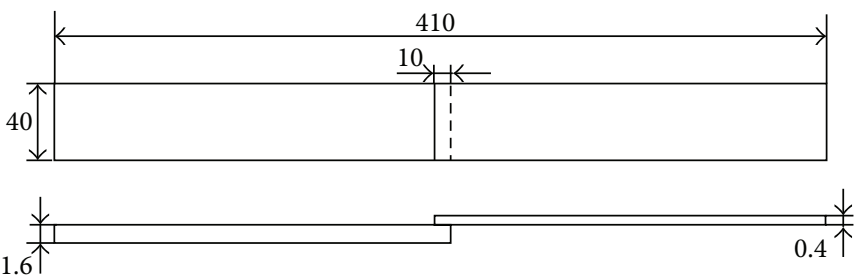

(b)

FIGURE 3: Geometric features of the fatigue specimen.

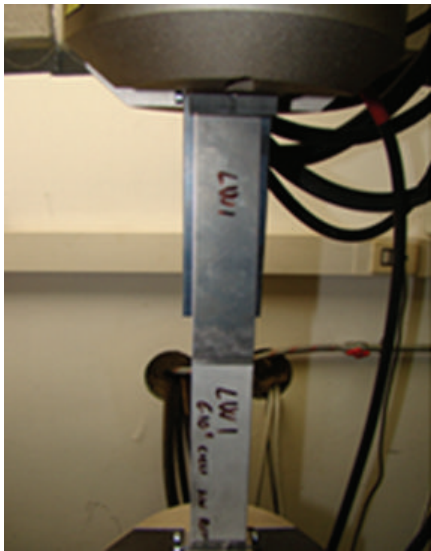

(a)

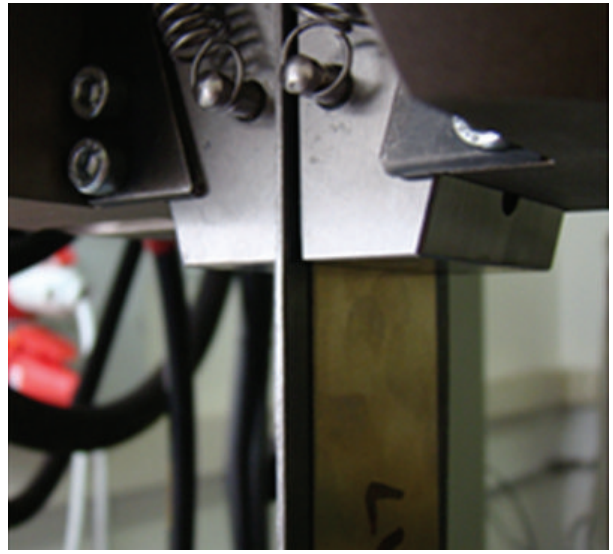

(b)

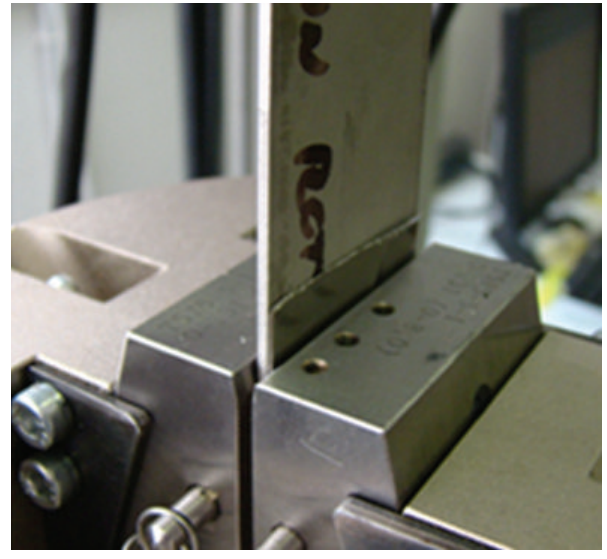

(c)

FIGURE 4: Specimen inserted in the machine grips and metallic tabs used.

To verify the achievement of this target, each weld was subjected to macrographic examination, performed with a Leica MZ6 modular stereomicroscope.

In the second part of the experimental test, mechanical properties of the specimens obtained from the welded sheets were investigated, with particular interest for the welds' fatigue behaviour. Parent material fatigue properties were also evaluated and compared to those for welds. In this case, Inconel 718 sheets, $1.6 \mathrm{~mm}$ thick, $40 \mathrm{~mm}$ wide, and between 190 and $200 \mathrm{~mm}$ long, were used. Static and dynamic tests were carried out on an Instron 8801 servo-hydraulic dynamic testing machine equipped with a $50 \mathrm{kN}$ load cell.

The weld static and fatigue behaviours were evaluated by testing rectangular cross section specimens, $40 \mathrm{~mm}$ wide, obtained by cutting the welded plates with a shearing machine (Figure 3). The load-bearing cross section was $28 \mathrm{~mm}^{2}$.

The specimens were inserted in the tensile machine grips by using two metallic tabs of 0.4 and $1.6 \mathrm{~mm}$. In order to avoid vibration of the thinner sheet at stress frequency, a longer metallic tab was used (Figure 4).

In this experimental session, a total of 33 test specimens (21 obtained from the welds and 11 from the parent material) were subjected to different sinusoidal stress cycles, characterized by a load ratio $\mu=0.1$ and a frequency $f$ of $10 \mathrm{~Hz}$.

The macro- and microstructures of the tested specimens were examined after the fatigue experimental section, by using a Leica MeF3 microscope.

All samples were mechanically polished using a diamond compound up to $1 \mu \mathrm{m}$ grain size and then etched with a solution composed of $50 \mathrm{cc} \mathrm{H}_{2} \mathrm{O}, 50 \mathrm{cc} \mathrm{HCl}$, and $1.2 \mathrm{cc}^{\mathrm{HNO}} \mathrm{H}_{3}$, heated to a temperature of between $70^{\circ}$ and $85^{\circ} \mathrm{C}$.

\section{Results and Discussion}

3.1. Characteristics of $\mathrm{CO}_{2}$ Laser Welding. The welding session highlighted some important correlations between the welding parameters (laser power and welding speed) and the geometrical joint aspects (welding penetration and weld width), in accordance with other experimental activities [4, 14, 15]. Looking at Figure 5(a), it is possible to notice that, for a constant value of welding speed, the joint dimensions (weld penetration and width) are directly proportional to the laser power input. Figure 5(b), instead, shows that, for a constant 


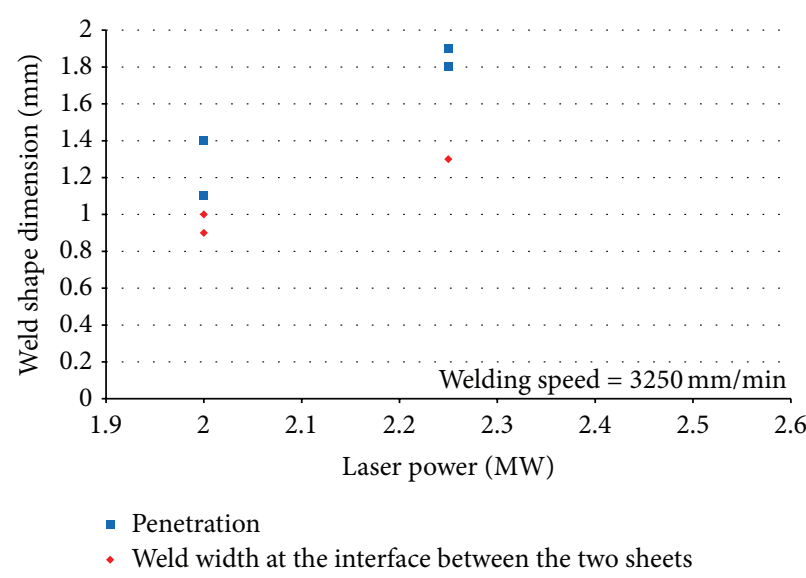

(a)

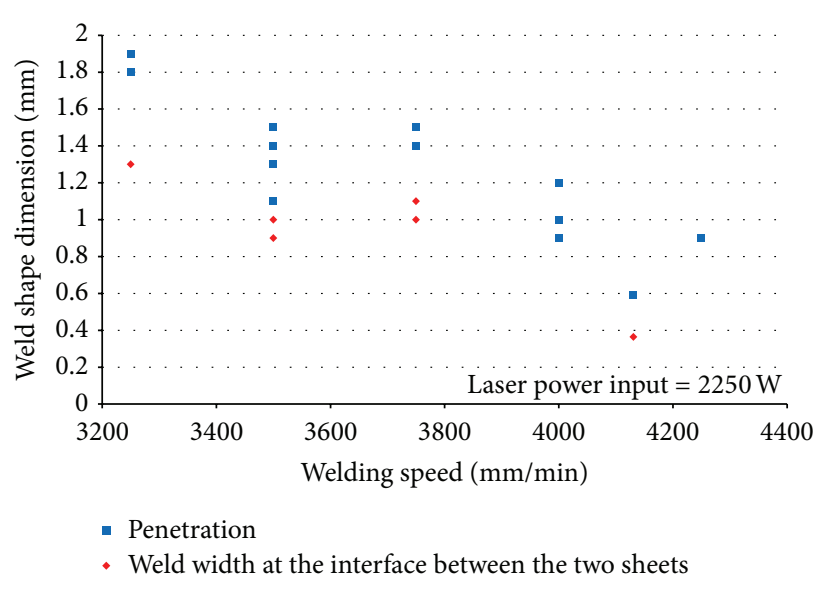

(b)

FIGURE 5: Penetration and width of welds in function of laser power (a) and of welding speed (b).

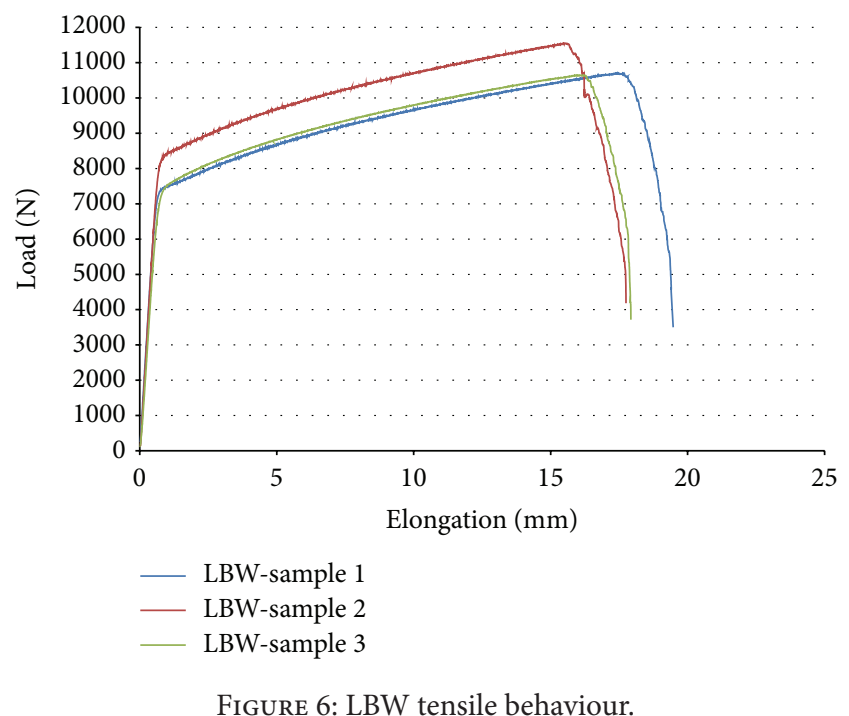

laser power input, the main dimensions of the joint are in inverse proportion to the welding speed.

From this welding campaign the optimal parameters to create the target geometry were chosen. In Table 2 the optimal joint shape was reported as well as the welding parameters used to create it.

3.2. Mechanical Properties and Fatigue Life Evaluation. The first part of the experimental session focused on the static characterization of the lap joints.

The tensile properties of the welds were assessed by testing three specimens obtained from the welded plates. The samples had the same geometry as the fatigue specimens, shown in Figure 3. The results of the tensile tests are reported in Figure 6. All the samples failed near the weld line on the thinnest sheet side.

As can be seen, the joints present good ductility, though it is obviously lower than the parent material [12]. The three samples showed good tensile strength, respectively, of 382.24 ,

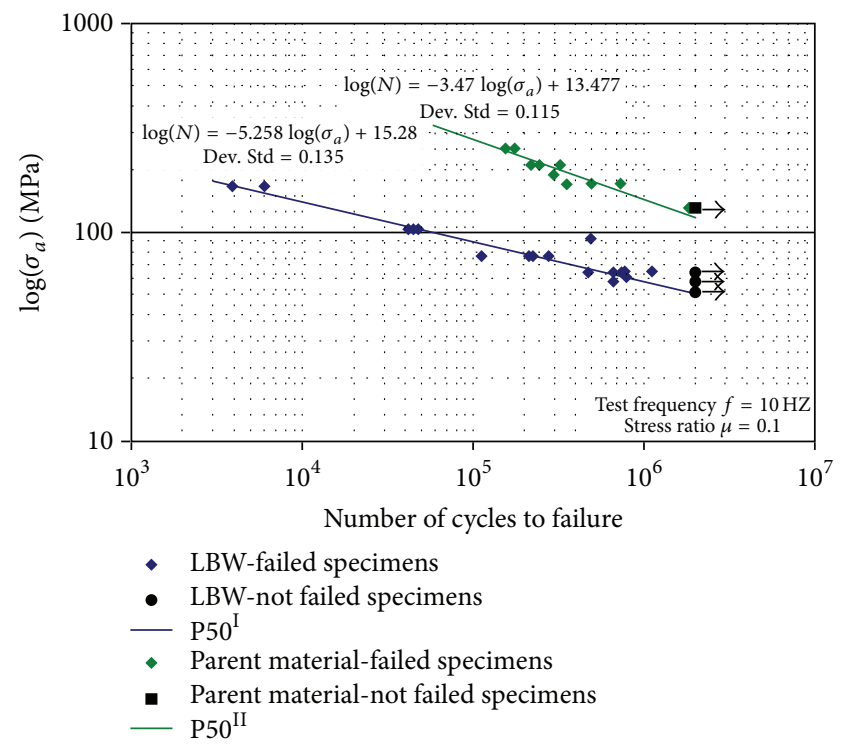

FIGURE 7: Fatigue behaviour of LBW and of Inconel 718.

380.27 , and $412.44 \mathrm{MPa}$, with a resulting average value of $391.65 \mathrm{MPa}$.

Then dynamic tensile tests were carried out to evaluate the behaviour of laser beam welds and also the parent material in terms of cyclic strength performance.

The data collected were processed and reported in a diagram (Figure 7), indicating the number of cycles to failure $(N)$ in function of the stress amplitude $\left(\sigma_{a}\right)$, allowing us to point out the fatigue life trend of the welds and of the Inconel 718.

In order to obtain a good demonstration of the joint fatigue behaviour, seven different stress amplitude levels were used, while only 5 stress levels were considered for the parent material.

In the case of the LBW, the first load step investigated $\left(\sigma_{a}=164.83 \mathrm{MPa}\right)$ resulted in an early fracture of the three 


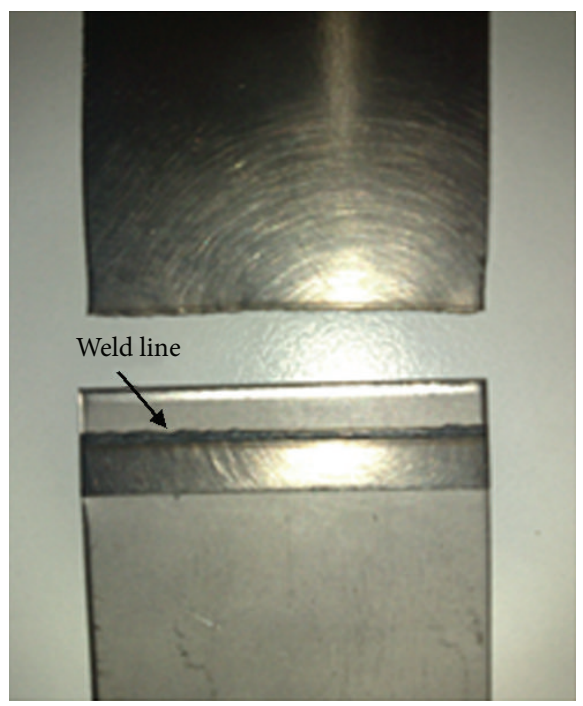

(a)

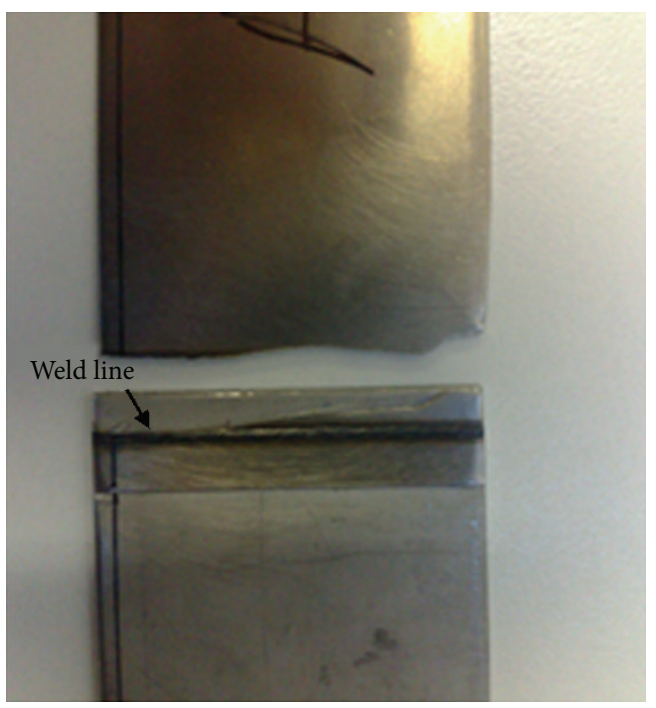

(b)

FIGURE 8: Failure modality of the fatigue specimens.

TABLE 2: Optimal welding parameters and resulting welded specimen.

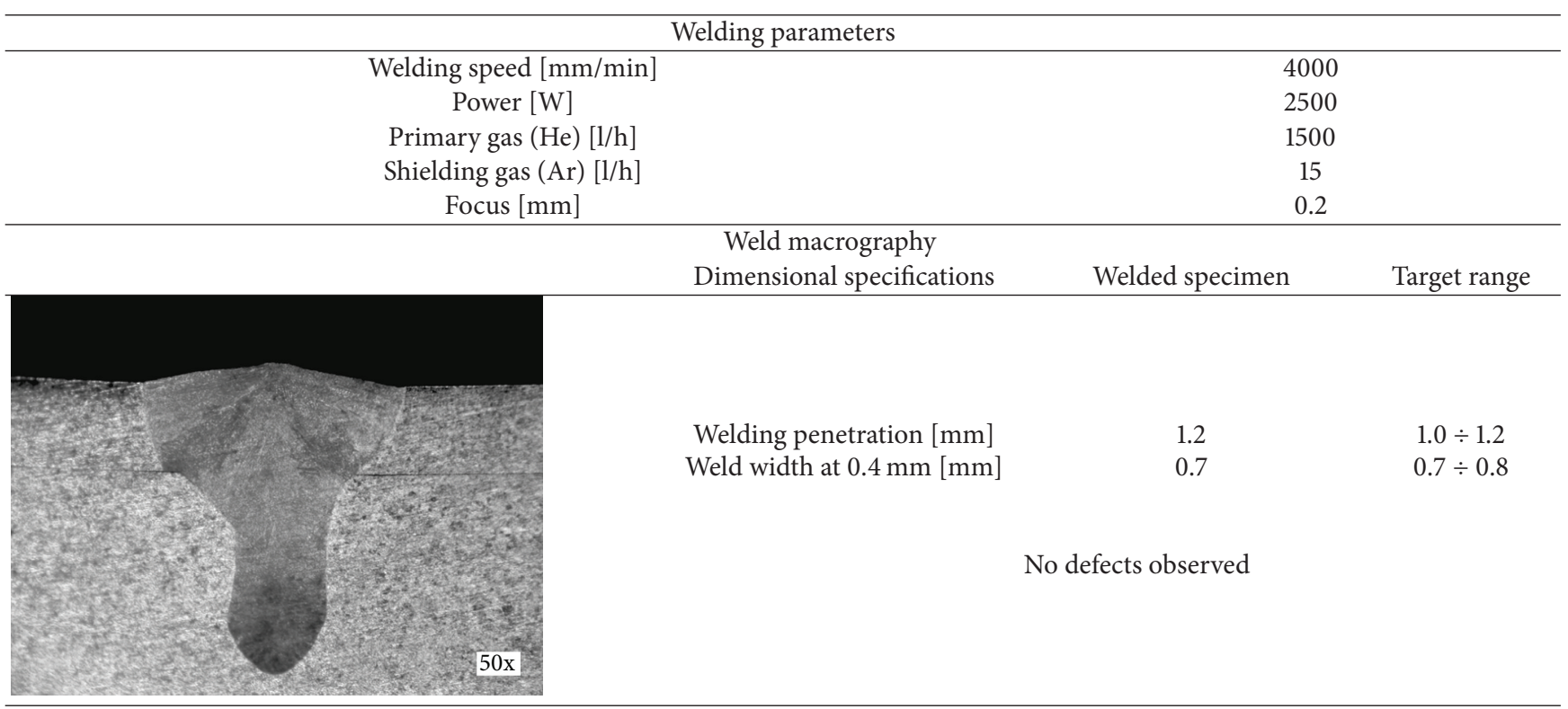

test samples, which failed after an average of only 4590 cycles. Hence, lower step levels were tested, in order to achieve a fatigue endurance of about $2 \cdot 10^{6}$ cycles, which was assumed to be the value representing an unlimited life of the joint.

A statistical study of the fatigue data was performed to define a linearized stress-life curve, as described by the standard practice reported in ASTM E 739-91 [16]. This method allowed definition of two curves-identified as "P50" and "P50" $\mathrm{II}$ " respectively, for the welds and for the parent material, corresponding to a survival probability of $50 \%$ for the specimens.

Analysis of these curves allowed us to define the fatigue limit of the LBW and of the Inconel 718, which turned out to be, respectively, 51 and $116.9 \mathrm{MPa}$.
From an analysis of the diagram, it is possible to notice a higher dispersion of the weld data compared to that of the parent material. This aspect is also confirmed by the higher standard deviation value of the laser beam specimens.

All the tested specimens failed in the same way: the crack started from the $0.4 \mathrm{~mm}$ Inconel sheet side, at the interface between the fused zone (FZ) and the base material (BM), which is a very narrow HAZ and developed along the weld line or in the base material, until the specimen was completely broken (Figure 8).

This specimen failure can be explained by considering the joint schematization reported in Figure 9, which highlights the weld resistant cross sections (grey zone), the fracture area (red zone), and the respective applied forces. 


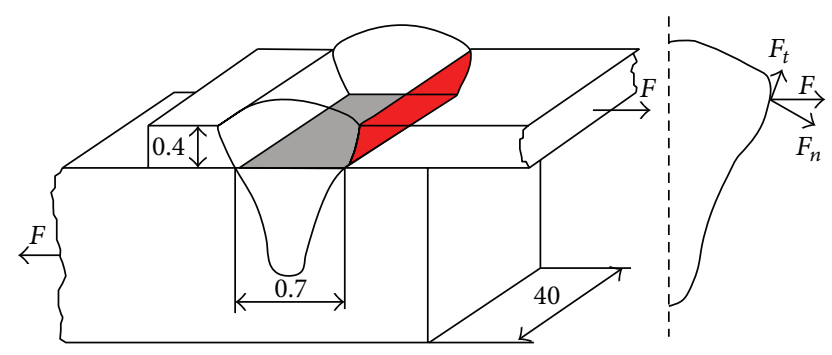

FIGURE 9: Welded cross section scheme and stress state at the interface between the joint and the base material.

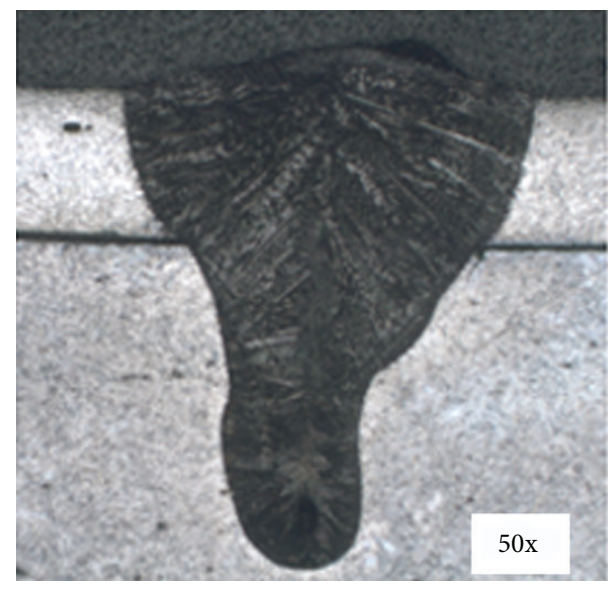

FIGURE 10: Laser beam weld macrography.

The grey zone is completely composed of material of the $\mathrm{FZ}$ and is subjected to shear stress by the applied load $F$. The failure area, instead, is basically composed of material of the HAZ and, due to its particular geometry, is subjected to a normal and a tangential component of the force $F$. Moreover, this area is narrower than the welded cross section: for these reasons, the fracture area is more stressed than the welded cross section.

3.3. Metallographic Analysis. In Figure 10, an example of the joint shape is reported: all welds are characterized by a bowl shape, with a tapered finger-like weld root.

Figure 11 highlights an isotropic base material microstructure, characterized by an equiaxic austenitic grain matrix in both transversal and longitudinal directions.

The high energy density of the laser beam process provides low heat input to the processed piece, resulting in a really narrow HAZ (Figure 12).

The FZ presents a dendritic microstructure, with a columnar grain shape, characterized by larger dimensions at the border with the HAZ and thinner toward the weld centre. This structure can be explained by the high thermal gradient associated with the fusion line, which promotes the growth of a continuous columnar dendritic structure close to the HAZ, while the rapid cooling rate and the reduction of the temperature difference with the surrounding material lead to the formation of a finer structure inside the FZ $[8,17]$.

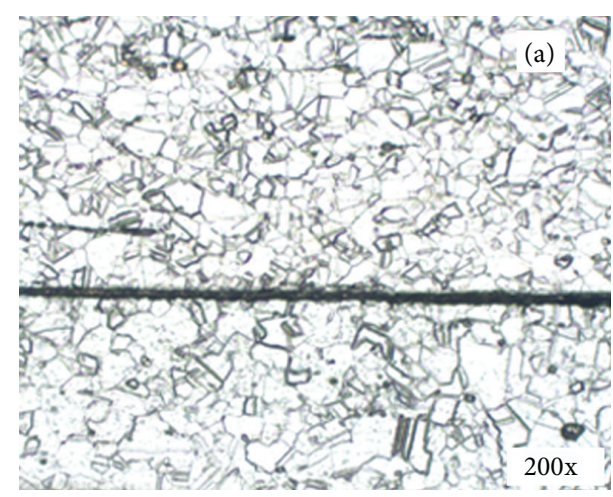

(a)

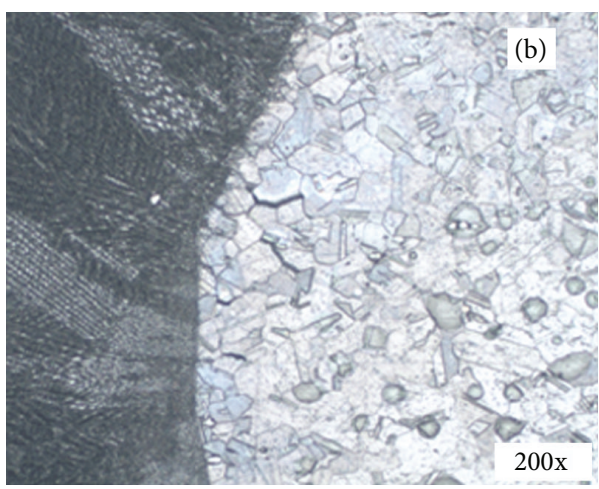

(b)

FIGURE 11: Base material microstructure of the transversal (a) and longitudinal (b) cross section.

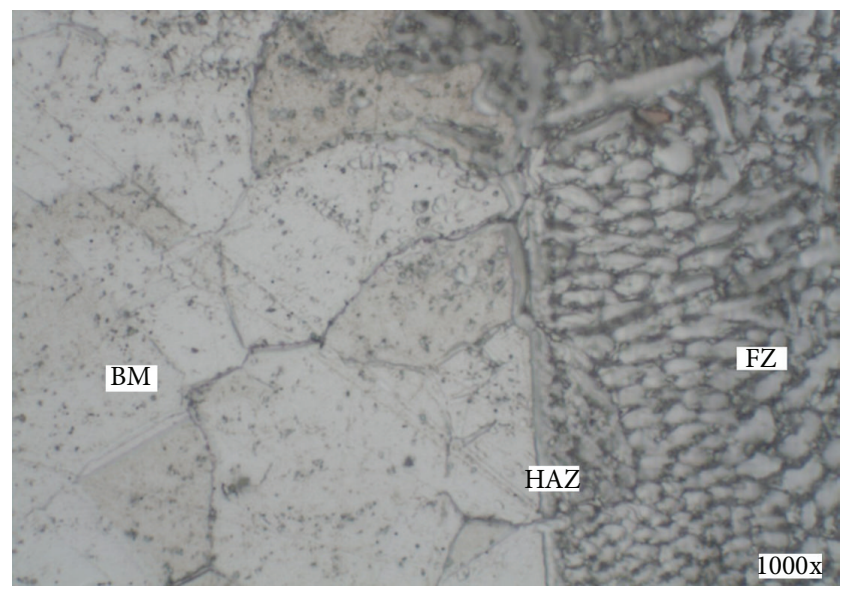

FIGURE 12: Microstructure of a LBW specimen.

Microcracks were observed in the HAZ, developing along a perpendicular direction with respect to the FZ (Figure 13).

The substitution of $\mathrm{Ti}$ and $\mathrm{Al}$ with $\mathrm{Nb}$ as strengthening elements in the precipitation-hardened alloy Inconel 718 improved the resistance to postweld heat-treatment stress relaxation cracking (PWHT), because of the sluggish precipitation of the hardening phase $[1,18,19]$. 

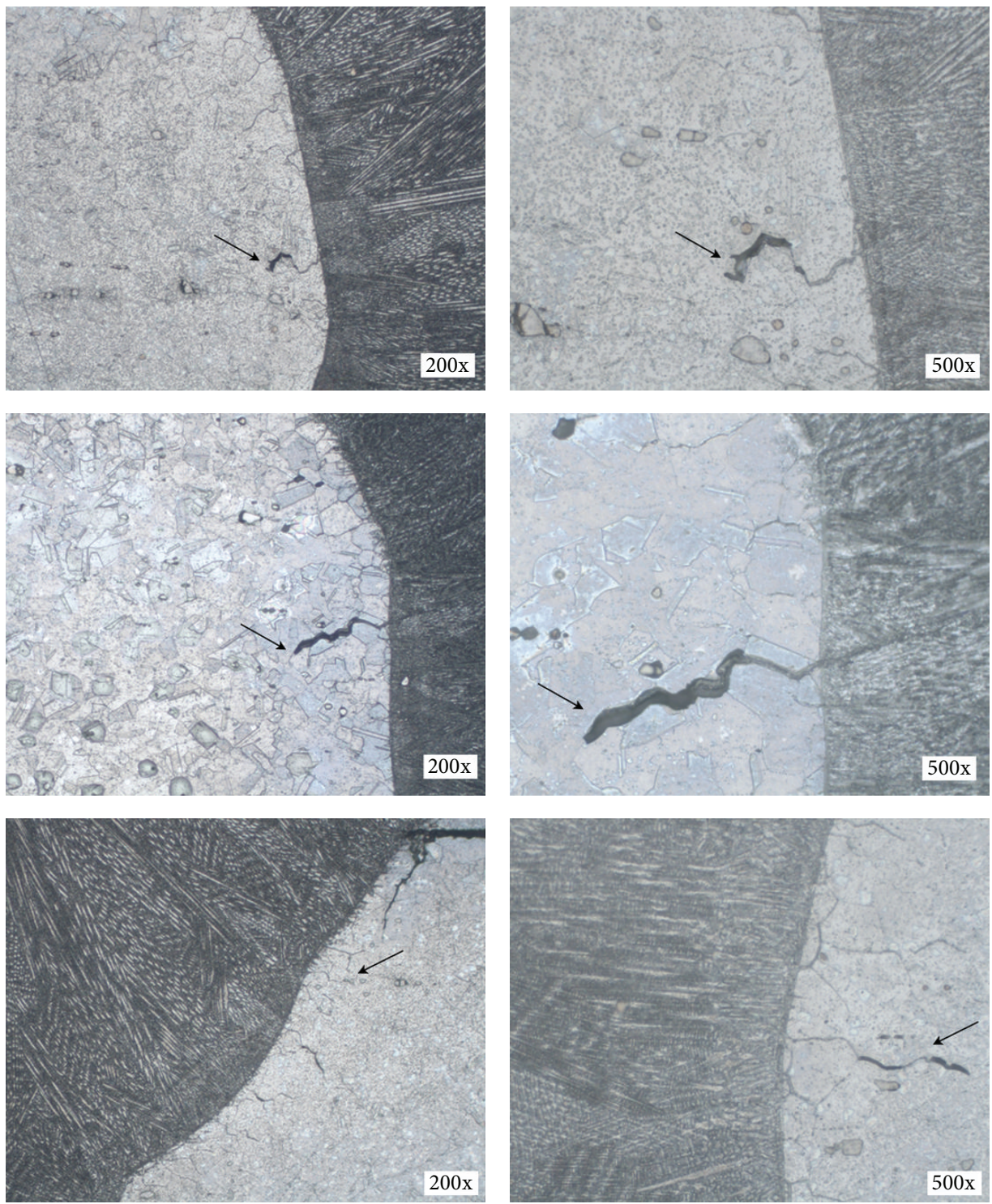

FIGURE 13: Microcracks in the HAZ at different magnifications.

On the other hand, many studies [6, 19-21] have highlighted a relationship between the presence of $\mathrm{Nb}$ and the formation of liquation cracking. This phenomenon is linked to the enrichment along the FZ grain boundaries in the $\mathrm{Nb}$ content, which is only partially solubilised in the HAZ due to the low heat input associated with LBW. This causes a lowering of the melting temperature and determines the formation of melted zones.

The presence of Boron in the material's chemical composition also promotes the liquation cracking susceptibility, as resulted from different investigations $[1,10,19,22]$. The segregation of this melting point depressant causes boundary liquation during welding, increasing the probability of microcrack formation associated with the presence of welding thermal stresses.

Thus, microcracks occur when the stress levels, generated by the welding thermal cycle, are high enough to separate the grains from each other, at the elongated grain tips of the dendritic structures, where stress concentration occurs.

The presence of this kind of defect would also explain the modality of failure of the fatigue specimens tested, which occurred at the interface between the HAZ and the FZ, where the presence of cracks is considerable.

Several studies have suggested possible solutions to microcrack formation in the HAZ. For example, Cantello et al. [7] explain the mechanism of grain refinement in cold and hot work materials very well, if the heat input during welding is high enough to produce a static recrystallization. Indeed, during this process the diffusion of Niobium stops and the new fine grains grow, without the deformation substructure, and this reduces the stress level of the microstructure, which limits the microcrack formation.

Another important parameter which influences the HAZ microcracking resistance is the average grain size $[9,19$, 21, 23]. Tested material revealed a coarse microstructure, 
characterized by a grain size of 4.3 , measured by planimetric procedure, in accordance with ASTM E112 [24]. This would also explain the high sensitivity to microcracking phenomena, verified in the welded samples.

\section{Conclusions}

In this study, the feasibility of an Inconel 718 laser beam lap joint, used for the manufacturing of a helicopter engine component, was verified.

The experimental tests highlighted high performances reached by a $\mathrm{CO}_{2} \mathrm{LBW}$ technique on this kind of alloy: the high energy density typical of this welding process minimizes the structural variation of the material, enabling conservation of most of its outstanding mechanical properties and very low distortion of the thin plates, necessary to properly operate in their extreme working conditions.

This research pointed out the following aspects.

(i) A full joint shape control is possible by carefully setting up the laser machine parameters.

(ii) The laser beam process allows one to preserve the high tensile strength and good ductility of Inconel 718, as results from the tensile tests performed.

(iii) The presence of the $\mathrm{Nb}$ and $\mathrm{B}$ contained in a metal matrix characterized by a coarse grain size, associated with a low heat input welding process, results in the generation of many liquation microcracks in the HAZ.

(iv) Besides the presence of the microcracks, the fatigue behaviour of the Inconel 718 overlap welds $(51 \mathrm{MPa}$, corresponding to an endurance of $2 \cdot 10^{6}$ cycles) complies with the technical specifications required by the project.

Moreover, this work allowed the collecting of important data about the fatigue resistance of lap joints of Inconel 718, which are difficult to find in the literature. Currently, most scientific work discusses thick-layer butt joints.

Further work to assess the influence of postwelding heat treatment in order to reduce the HAZ microcracks could be performed trying to limit the deformation of the finished piece as much as possible.

\section{Conflict of Interests}

All the authors declare that there is no conflict of interests regarding the publication of this paper.

\section{Acknowledgments}

The authors thank Piaggio Aero Industries S.p.A for supplying the material and the IIS for its support during the welding.

\section{References}

[1] D. J. Tillack, "Welding superalloys for aerospace applications," Welding Journal, vol. 86, no. 1, pp. 28-32, 2007.
[2] The Metals Red Book: Volume 2: Nonferrous Metals, Casti Publishing, 2003.

[3] Y. S. Yang and S. H. Lee, "Study on the joining strength of laser spot welding for automotive applications," Journal of Materials Processing Technology, vol. 94, no. 2, pp. 151-156, 1999.

[4] Q. Wu, J. Gong, G. Chen, and L. Xu, "Research on laser welding of vehicle body," Optics and Laser Technology, vol. 40, no. 2, pp. 420-426, 2008.

[5] I. Rotzer, "Laser-beam welding makes aircraft lighter," Fraunhofer Magazine, vol. 1, pp. 36-37, 2005.

[6] S. Gobbi, L. Zhang, J. Norris, K. H. Richter, and J. H. Loreau, "High powder $\mathrm{CO}_{2}$ and Nd-YAG laser welding of wrought Inconel 718," Journal of Materials Processing Technology, vol. 56, no. 1-4, pp. 333-345, 1996.

[7] M. Cantello, G. Ricciardi, and S. L. Gobbi, "Laser welding of superalloys for the manufacturing of aeroengine components," CIRP Annals-Manufacturing Technology, vol. 45, no. 1, pp. 173178, 1996.

[8] G. D. J. Ram, A. V. Reddy, K. Prasad Rao, G. M. Reddy, and J. K. S. Sundar, "Microstructure and tensile properties of Inconel 718 pulsed Nd-YAG laser welds," Journal of Materials Processing Technology, vol. 167, no. 1, pp. 73-82, 2005.

[9] J. K. Hong, J. H. Park, N. K. Park, I. S. Eom, M. B. Kim, and C. Y. Kang, "Microstructures and mechanical properties of Inconel 718 welds by $\mathrm{CO}_{2}$ laser welding," Journal of Materials Processing Technology, vol. 201, pp. 515-520, 2008.

[10] K. R. Vishwakarma, N. L. Richards, and M. C. Chaturvedi, "Microstructural analysis of fusion and heat affected zones in electron beam welded ALLVAC 718PLUS superalloy", Materials Science and Engineering A, vol. 480, no. 1-2, pp. 517-528, 2008.

[11] A. Squillace, U. Prisco, S. Ciliberto, and A. Astarita, "Effect of welding parameters on morphology and mechanical properties of Ti-6Al-4V laser beam welded butt joints," Journal of Materials Processing Technology, vol. 212, no. 2, pp. 427-436, 2012.

[12] ASTM, "Standard specification for precipitation-hardening nickel alloy (UNS N07718) plate, sheet, and strip for high-temperature service," ASTM B 670-02, 2002.

[13] W. L. Mankins and S. Lamb, "Nickel and nickel alloys," in Properties and Selection: Nonferrous Alloys and Special-Purpose Materials, vol. 2 of Metals Handbook, pp. 1366-1377, ASM International, 10th edition, 1990.

[14] A. M. El-Batahgy, "Effect of laser welding parameters on fusion zone shape and solidification structure of austenitic stainless steels," Materials Letters, vol. 32, no. 2-3, pp. 155-163, 1997.

[15] E. Akman, A. Demir, T. Canel, and T. Sinmazçelik, "Laser welding of Ti6Al4V titanium alloys," Journal of Materials Processing Technology, vol. 209, no. 8, pp. 3705-3713, 2009.

[16] ASTM E739-10, "Standard Practice for Statistical Analysis of Linear or Linearized Stress-Life $(\mathrm{S}-\mathrm{N})$ and Strain-Life $(\varepsilon-\mathrm{N})$ Fatigue Data".

[17] S. A. David, S. S. Babu, and J. M. Vitek, "Welding: solidification and microstructure," JOM, vol. 6, pp. 14-20, 2003.

[18] D. W. J. Tanner, Life assessment of welded Inconel 718 at high temperature [Ph.D. thesis], University of Nottingham, Nottingham, UK, 2009.

[19] M. B. Henderson, D. Arrell, M. Heobel, R. Larsson, and G. Marchant, "Nickel based superalloy welding practices for industrial gas turbine applications," Science and Technology of Welding \& Joining, vol. 9, no. 1, pp. 13-21, 2004.

[20] G. D. Smith and S. J. Patel, "The role of niobium in wrought precipitation-hardened nickel-base alloys," in Proceedings of the 
6th International Symposium on Superalloys 718, 625, 706 and Derivatives, pp. 135-154, TMS, Warrendale, Pa, USA, October 2005.

[21] A. Lingenfelter, Welding of Inconel Alloy 718: A Historical Overview, Superalloy 718, Metallurgy and Applications, TMS, 1989.

[22] H. Guo, M. C. Chaturvedi, N. L. Richards, and G. S. McMahon, "Interdependence of character of grain boundaries, intergranular segregation of boron and grain boundary liquation in simulated weld heat-affected zone in inconel 718," Scripta Materialia, vol. 40, no. 3, pp. 383-388, 1999.

[23] A. Gregori, "A survey of welding and repairing of nickel superalloys for gas turbines," Tech. Rep. 774, TWI, 2003.

[24] ASTM, "Standard test methods for determining average grain size," ASTM E112-13, 2013. 

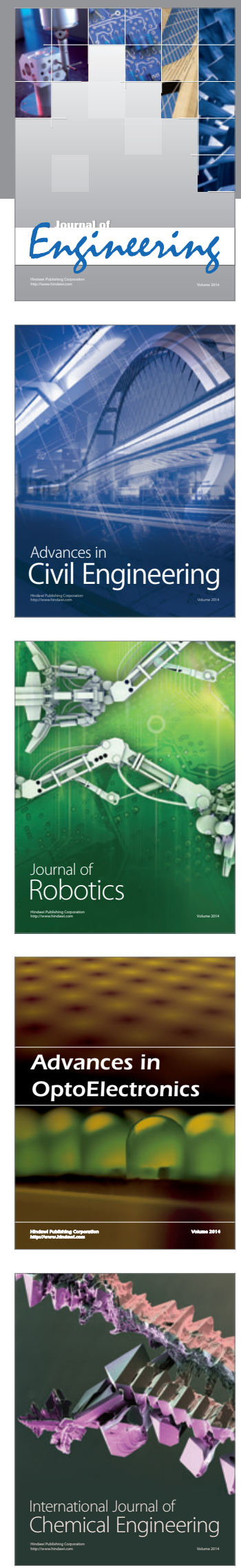

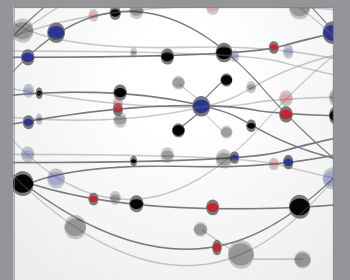

The Scientific World Journal
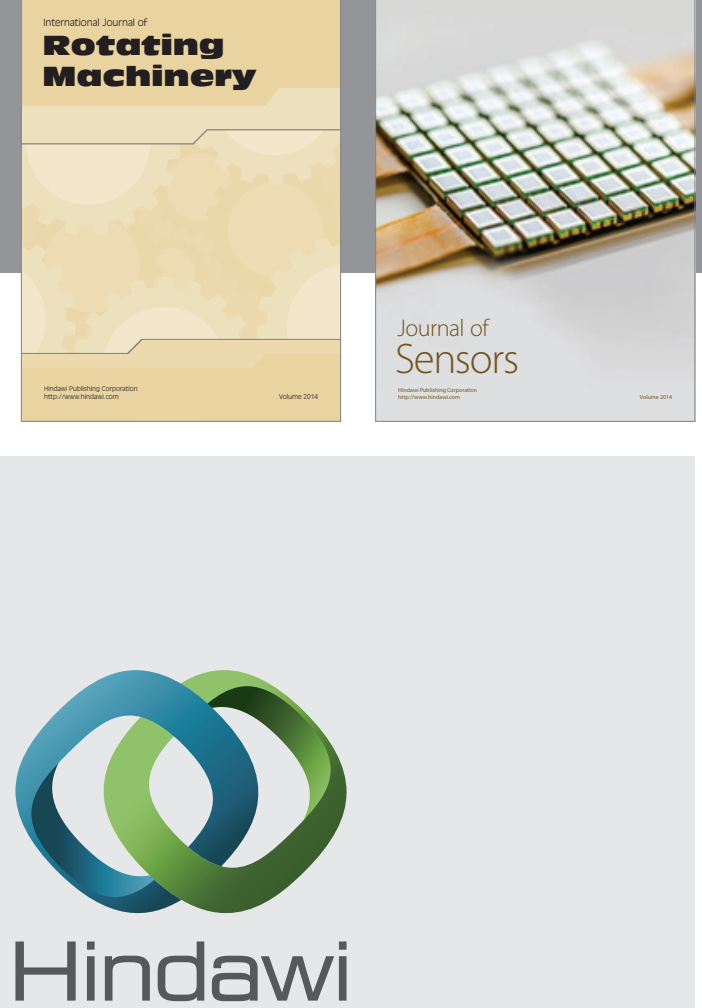

Submit your manuscripts at http://www.hindawi.com
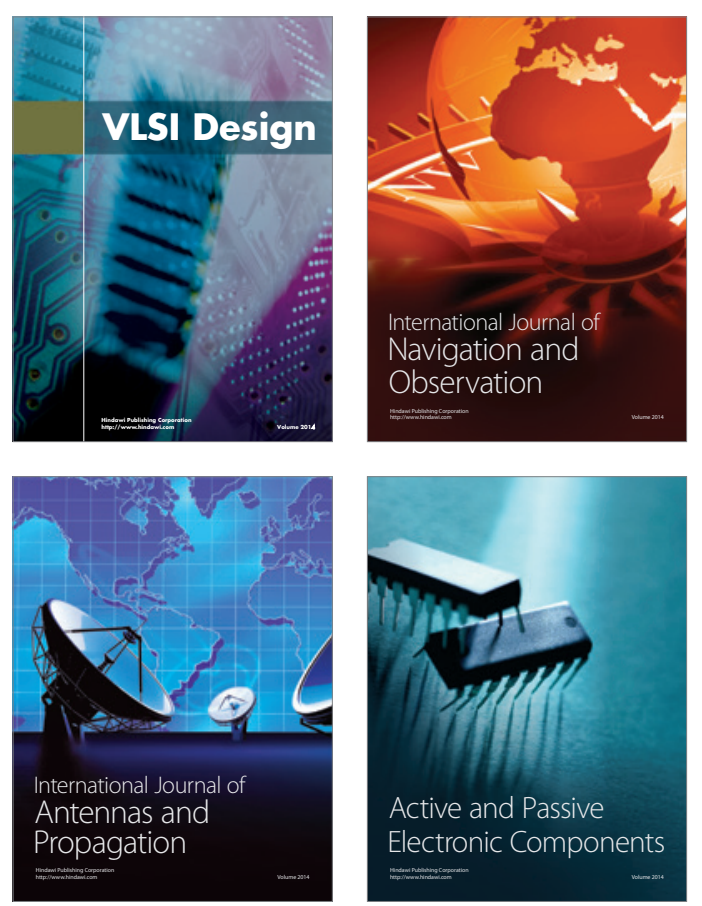
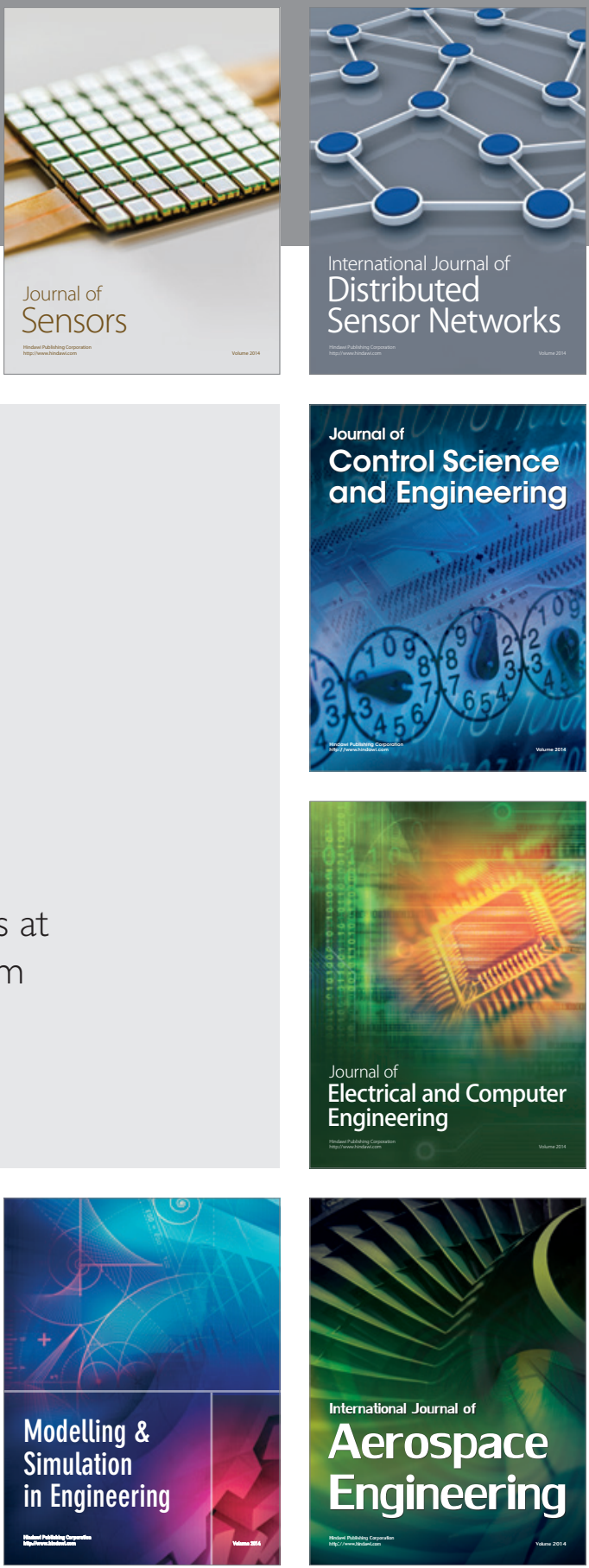

Journal of

Control Science

and Engineering
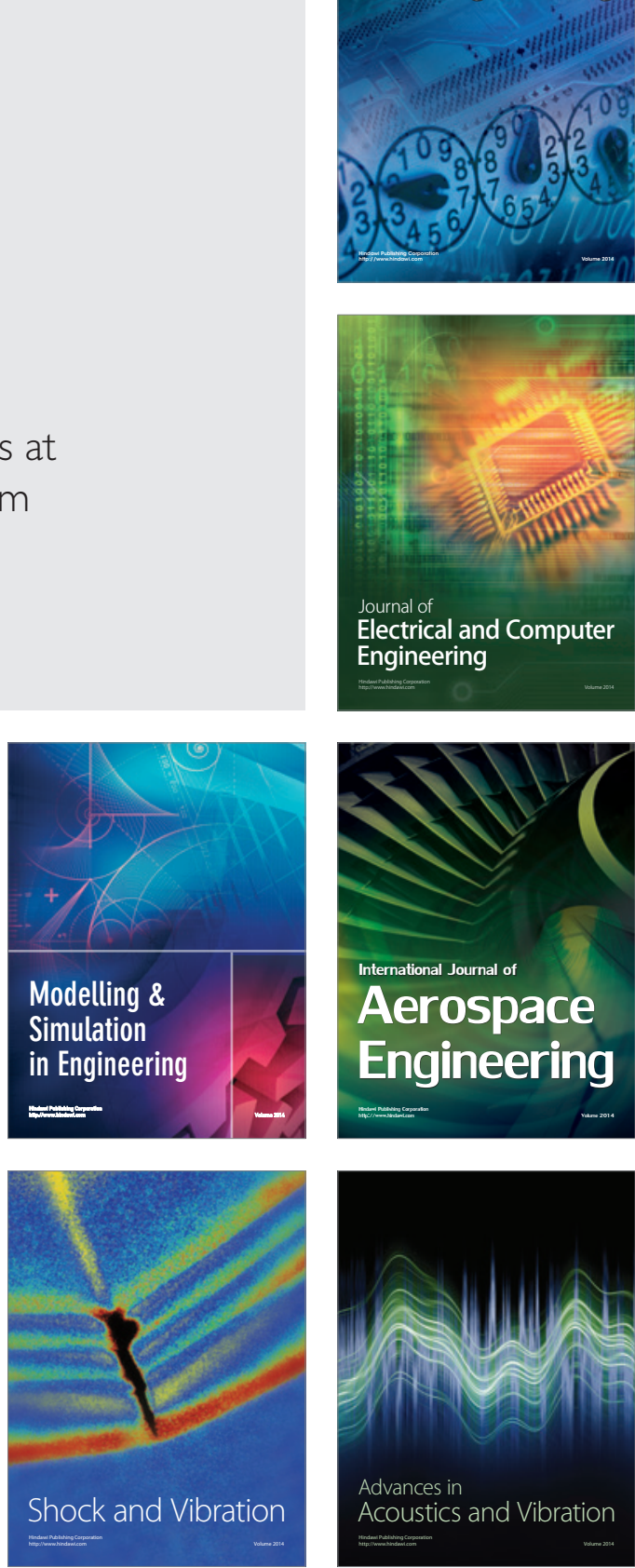